\title{
RECATEGORIZAÇÃO E CONSTRUÇÃO DO SENTIDO EM TEXTOS MULTIMODAIS
}

\author{
Elaine Cristina Forte-Ferreira ${ }^{1}$ \\ Vicente de Lima-Neto ${ }^{2}$
}

\section{RESUMO}

Embora existam estudos sobre elementos multimodais há mais de uma década na Linguística, apenas nos últimos cinco anos a Linguística de Texto passou a levar em consideração recursos semióticos distintos do verbal em suas análises textuais/discursivas. Este artigo tem como objetivo investigar como recursos multimodais podem também ser tratados como expressões referenciais que recategorizam objetos do discurso. Para isso, investigou-se um corpus de dez textos multimodais que foram publicados em sites de rede social e em sites humorísticos e que tinham como característica recategorizarem o referente. Os resultados apontam que os elementos visuais pertencentes à composição de textos multimodais também são fulcrais para a construção do sentido do texto, de maneira que muitas vezes são eles os responsáveis pelo processo de recategorização.

Palavras-chave: Construção de sentido. Recategorização. Textos multimodais.

\section{CONSIDERAÇÕES INICIAIS}

Embora a Linguística de Texto (LT) já tenha mais de trinta anos de estudos no Brasil, a atenção que se tem dado às características multimodais do texto é bastante recente. Kress e Van Leeuwen (1996) estão entre os primeiros que incluíram nos estudos do discurso o sentido das imagens na composição textual. Entretanto, a linha de pesquisa em que construíram a sua Gramática do Design Visual é a Semiótica Social, com raízes na Linguística Sistêmico Funcional, que nem sempre dialoga com as bases epistemológicas da LT.

Esta preocupação apenas na última década tem entrado na agenda de estudos da LT no Brasil (BENTES; ALVES FILHO e RAMOS, 2010) e vem ganhando força, já que o olhar que se dá ao texto hoje não pode ignorar o fato de cada vez mais eles serem constituídos por semioses distintas, além da verbal.

A proposta deste trabalho é mostrar como quão importantes são os recursos multimodais na construção do sentido, principalmente quando são eles os responsáveis pela recategorização do referente no discurso. 
Organizamos este trabalho em quatro subseções, além destas considerações iniciais: num primeiro momento, detivemo-nos na constituição do texto multimodal quais as suas características e como ele vem sendo tratado na literatura -; num segundo momento, fizemos um resgate dos tipos de conhecimentos necessários para a construção do sentido de um texto, seguindo as bases da LT; num terceiro momento, discorremos sobre o fenômeno da recategorização e, por fim, mostramos como os elementos multimodais podem servir para recategorizar um referente no discurso.

\section{A CONSTITUIÇÃO DO TEXTO MULTIMODAL}

Koch (2004) desenvolve um longo histórico da Linguística Textual no qual é possível perceber por quantas definições o conceito de texto passou e, até hoje, parece ser praticamente impossível estabelecer uma definição que atenda a todas as peculiaridades da área. Atualmente, uma das mais aceitas é a concepção de base sociocognitivista:

[...] na concepção interacional (dialógica) da língua, na qual os sujeitos são vistos como atores/construtores sociais, o texto passa a ser considerado o próprio lugar da interação e os interlocutores, sujeitos ativos que dialogicamente - nele se constroem e por ele são construídos. A produção de linguagem constitui atividade interativa altamente complexa de produção de sentidos que se realiza, evidentemente, com base nos elementos linguísticos [grifos nossos] presentes na superfície textual e na sua forma de organização, mas que requer não apenas a mobilização de um vasto conjunto de saberes (enciclopédia), mas a sua reconstrução e a dos próprios sujeitos - no momento da interação verbal. $(\mathrm{KOCH}, 2004$, p. 3233).

Como se vê, para esta perspectiva, o que garante o estatuto do texto são seus elementos linguísticos e sua forma de organização, o que, de certa forma, não permitiria que enunciados que não apresentem em sua constituição uma linguagem verbal fossem reconhecidos como texto.

Parece ser difícil construir sentido de um texto que apresente outros elementos alheios à escrita, como uma história em quadrinhos ou uma charge, se forem isolados os elementos linguísticos. Intuitivamente unimos elementos imagéticos e verbais para compreendermos textos que envolvem linguagens distintas. Este é um procedimento sociocognitivo que mobiliza muitos conhecimentos, dentre eles o enciclopédico, do qual falaremos à frente, que 
comporta toda a nossa experiência de mundo - inclusive aquelas em que utilizamos letramentos visuais para entender algo no mundo. Esta é uma das premissas da Semiótica Social que tem suas raízes ainda na década de 1980, com Hodges e Kress (1988), os quais entendem que aqueles textos são constituídos por mais de um código semiótico como textos multimodais.

Embora não sigamos essa orientação epistemológica neste trabalho, podemos dizer que o atual posicionamento da LT sobre o conceito de texto compartilha esta premissa da Semiótica Social. Bentes, Ramos e Alves (2010) já haviam apontado a necessidade de uma rediscussão sobre o conceito, já que os aspectos multimodais parecem ser objetos "desafiadores" para a compreensão dos textos atualmente. Para eles, é necessário "um alargamento do conceito de texto, de modo a incorporar nele elementos não verbais (imagem, cor etc)" e "o emprego de dispositivos analíticos oriundos do campo de estudos do texto, que permita trabalhar com tais signos". (BENTES; ALVES FILHOS e RAMOS, 2010, p. 398).

Não significa dizer que os elementos semióticos alheios à linguagem verbal são novos; pelo contrário, são, inclusive, anteriores à escrita, entretanto, apenas agora se tem dado um caráter científico àquilo que faz parte da essência do ser humano e de suas relações com o mundo.

Em suma, embora a LT esteja centrando suas atenções para aspectos não tão novos na composição dos textos - dentre eles os recursos imagéticos -, parece ainda haver certa falta de critérios para dar conta desses novos elementos. Isso é natural, já que não havia preocupações assim antes da década de 2000. Custódio Filho e Cavalcante (2010) dão a sua contribuição para o conceito, quando propõem um refinamento da definição de Koch (2004):

A produção de linguagem [verbal e não verbal] constitui atividade interativa altamente complexa de produção de sentidos que se realiza, evidentemente, com base nos elementos [linguísticos] presentes na superfície textual e na sua forma de organização, mas que requer não apenas a mobilização de um vasto conjunto de saberes (enciclopédia), mas a sua reconstrução e a dos próprios sujeitos - no momento da interação verbal. (CUSTÓDIO FILHO e CAVALCANTE, 2010, p. 9).

Dessa maneira, retirando os elementos "linguísticos" e "verbal" e alargando o termo "linguagem" para dar conta tanto de elementos verbais quando de não verbais, tem-se um ajustamento de um conceito que, agora, atende a textos constituídos por mais de um modo semiótico. 
À luz desse pensamento, as investigações que se têm feito presentes na LT sobre textos multimodais recaem principalmente sobre os estudos da Referenciação ${ }^{3}$, como maneira de rever determinados posicionamentos até então bem consolidados na literatura. Com essa nova perspectiva, algumas temáticas têm merecido destaque, como os processos referenciais (PINHEIRO, 2012; RAMOS, 2012), a construção do sentido (CAVALCANTE, 2012) e a recategorização (CUSTÓDIO FILHO, 2012), assuntos estes de nosso interesse.

\section{TIPOS DE CONHECIMENTO PARA A CONSTRUÇÃO DO SENTIDO}

Não é novidade que o processo de produção e de interpretação textual desperta a curiosidade de estudiosos da linguagem. Contudo, mesmo com todos os avanços da LT, podemos dizer que a atividade de apreender o sentido das imagens numa determinada composição textual ainda hoje constitui um desafio.

Será que a complexidade desse processo seria decorrente da dependência de estratégias sociocognitivas para a construção de sentidos? Uma vez consolidada a necessidade de recorrermos a elas, consideramos fundamental tentar distinguir os diversos tipos de conhecimentos que são requeridos para a construção de sentido, seja para a compreensão ou para a produção de textos.

Segundo Koch e Elias (2006), existem três tipos de conhecimento: o linguístico, o enciclopédico ou de mundo e o interacional. A seguir, faremos uma explanação acerca de cada um deles com base em Koch e Elias (2006), Cavalcante (2012) e nos estudos realizados pelo grupo Protexto.

\subsection{Conhecimento linguístico}

Relaciona-se não apenas ao domínio do sistema linguístico, englobando as noções semânticas, sintáticas, morfológicas, estilísticas etc., mas também aos conhecimentos que o sujeito adquiriu durante sua vivência e que serão indispensáveis para que a construção do sentido seja concretizada em aliança aos conhecimentos discursivos. Vejamos: 


\section{O CUME}

No alto daquele cume

Plantei um pé de roseira. O mato no cume cresce, A rosa no cume cheira.

Quando cai a chuva fria Salpicos no cume caem, Lagartas no cume entram, Abelhas do cume saem.

Mal cai a chuva grossa A água no cume desce, $\mathrm{O}$ orvalho no cume brilha, A flor no cume cresce.

E depois a chuva cessa Ao cume volta alegria, Voltou a brilhar depressa $O$ sol, que no cume ardia.

E à hora crepuscular Tudo no cume escurece, Vagalumes do cume saem, Estrelas no cume aparecem...

Fonte: http://www.recantodasletras.com.br/humor/2288819

Para que o sentido seja construído neste poema, é necessário considerar a ambiguidade, recurso responsável por gerar o riso no exemplo em tela. Neste texto, as palavras escolhidas ocasionam a mudança de sentido quando são lidas, pois são organizadas sintaticamente de modo que gere uma cacofonia. O terceiro verso, por exemplo, apresenta uma cacofonia de modo que pode ser lido "O mato no cu me cresce", obviamente levando o leitor ao riso. Neste caso, o leitor proficiente precisa do conhecimento linguístico para construir sentido, embora se saiba que essa mudança não é resultante somente dos elementos linguísticos presentes, mas também da junção que é realizada entre esses elementos e o efeito resultante da ambiguidade entre as palavras. Além disso, esse efeito também será somado ao conhecimento enciclopédico do leitor, ou seja, outros conhecimentos terão de ser ativados para que a construção de sentido seja concretizada e, consequentemente, o propósito do gênero, no caso poema, com finalidades puramente humorísticas, seja alcançado. 


\subsection{Conhecimento enciclopédico ou de mundo}

Este conhecimento pode ser apreendido também de maneira informal, ou seja, não precisa do rigor metodológico requerido no processo de ensinoaprendizagem, na maioria das vezes, presente na instituição escolar. Isso significa dizer que ele pode ser adquirido durante nossas experiências de mundo mais corriqueiras. Ao realizarmos uma leitura, acionamos esses conhecimentos que, muitas vezes, são imprescindíveis para entendermos o sentido do texto. Observemos o exemplo a seguir.

\section{A televisão da loira \\ Por que a loira colocou fogo na televisão??? \\ R: Porque ela queria assistir Tela Quente!!}

Fonte: http://piadasengracadas.net/piada/1398/a-televisao-da-loira

O texto requer que o leitor partilhe das informações presentes em piadas quando diz respeito às mulheres loiras, as quais, nesse contexto humorístico, são consideradas pessoas estúpidas, com dificuldades de discernimento e compreensão. Também se faz necessário conhecer o programa televisivo Tela Quente, que exibe filmes, e acreditamos que tenha essa nomenclatura por desejar despertar a vontade de o telespectador assistir a um bom filme ou filme "quente", aproveitando-se do fato de, em nossa cultura, o termo quente poder ser interpretado metaforicamente como bom.

Assim, para que o gênero alcance o efeito pretendido, é evidente a alusão à "ignorância da mulher loira", que, nesse caso específico, ao colocar fogo na televisão, mostrou que não sabe estabelecer a diferença entre o sentido metafórico e o literal do termo "quente". Como já foi ressaltado por Cavalcante (2012), esse tipo de conhecimento, que, de certa maneira, força o leitor a recuperar seus conhecimentos culturais e/ou sociais, relaciona-se bastante ao que Koch e Elias (2006) designam por conhecimento interacional.

\subsection{Conhecimento interacional}

Esse tipo de conhecimento precisa ser acionado para que saibamos interagir nas mais diversas situações comunicativas. É o domínio desse conhecimento que proporcionará o "saber agir" nos mais variados eventos de comunicação. Vejamos: 


\section{Figura 1 - Fórum educacional}

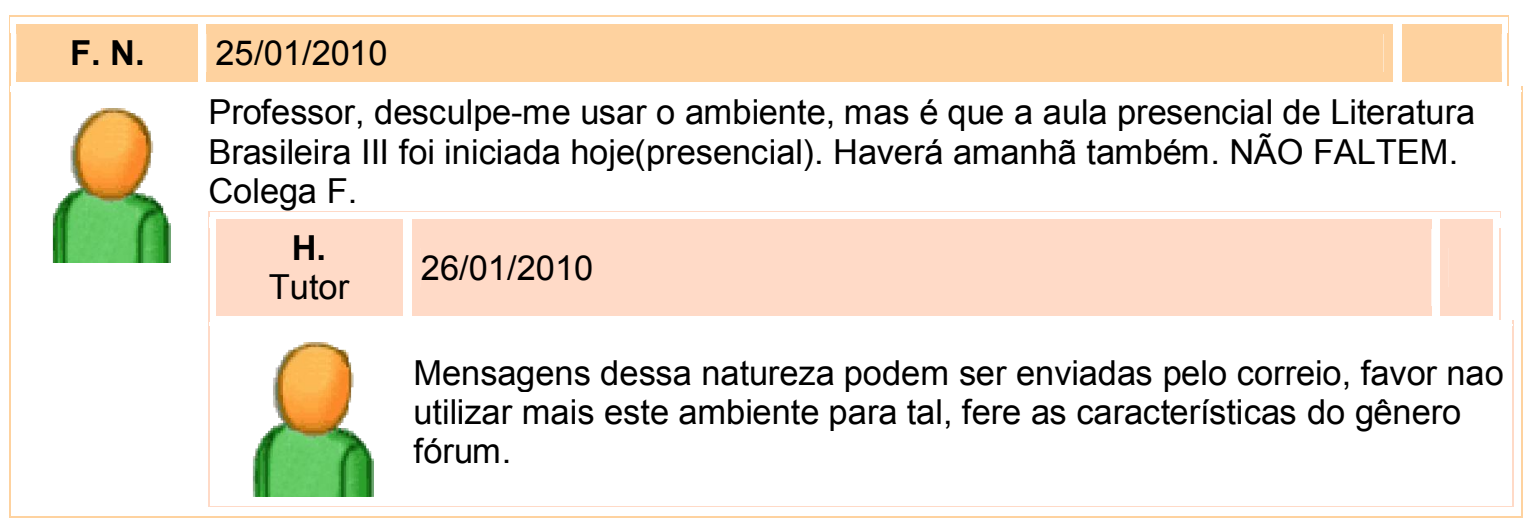

Fonte: www.solar.ufc.br

Neste exemplo, temos um fórum educacional de uma disciplina específica ministrada em curso semipresencial. Nele, um aluno posta uma mensagem para os colegas sobre outra disciplina, o que faz com que ele sofra uma coerção por parte do tutor, já que se quebra o princípio da relevância. Como consequência dessa ruptura, o tutor faz intervenção na tentativa de mostrar ao aluno que tal situação não permite o envio de mensagem daquela natureza para a turma, justamente pelo fato de o gênero ter um propósito definido, o qual é alheio ao que ele, aluno, tenta lhe agregar.

É interessante destacar que o aluno demonstra conhecer o gênero fórum educacional, isso é comprovado pelo fato de se desculpar pela utilização inapropriada do gênero. Entretanto, podemos dizer que, ao usar indevidamente o gênero, o aluno não utilizou o conhecimento interacional a seu favor.

Embora Cavalcante e Santos (2012) corroborem com Santos, Cuba Riche e Teixeira (2012) acerca da existência de outros conhecimentos (textual, intertextual e contextual), entendemos que estes estariam incluídos no conhecimento enciclopédico. É importante destacar que a separação que realizamos tem finalidade organizacional e didática, pois não é possível separar os conhecimentos durante a construção de sentido do texto.

Portanto, as análises realizadas pela LT, quando se busca a construção do sentido, atualmente têm em sua base os três tipos de conhecimento que aqui elencamos. São eles que também precisam ser levados em consideração quando um objeto de discurso é construído numa interação, o qual também pode ser recategorizado, e é este tipo de fenômeno que constitui o objeto deste artigo. 


\section{RECATEGORIZAÇÃO}

Dentre variados tipos de conhecimento para a construção do sentido do texto, ressalta-se o fenômeno da recategorização, estratégia referencial cujo conceito tem passado por modificações nos últimos quinze anos. Aphotelóz e Reichler-Béguelin (1995) consideravam-na como um recurso referencial que modifica um referente já introduzido no discurso, conduzindo a "uma informação inédita [...] que pode eventualmente desencadear uma reinterpretação do que precede" (APHOTELÓZ e REICHLER-BÉGUELIN, 1995, p. 231). Embora seja uma abordagem que se limita ao emprego de expressões referenciais para justificar a reinterpretação do texto, ela é a fundadora dos estudos da recategorização e não está incólume a críticas. Como argumenta Lima (2009, p. 40), "na concepção dos autores, seria impróprio pensar em ocorrências de recategorizações ancoradas em referentes construídos ou inferidos fora da materialidade textual".

Cavalcante (2004), por exemplo, já considera o fenômeno como um "processo cognitivo-discursivo mais amplo, em que as modificações por que passa o objeto referido se revelam em variados índices cotextuais e podem, por meio deles, ser reconstruídas pelo ouvinte" (CAVALCANTE, 2004, p.1). Neste caso, a autora propõe que se dê um viés mais discursivo ao fenômeno, de maneira que as expressões referenciais não sejam os elementos sob os quais a recategorização deve ser marcada. A autora traz, então, a seguinte proposta:

A'recategorização' é, por definição, uma alteração nas associações entre representações categoriais parcialmente previsíveis, portanto, em nossa visão pública de mundo. A menor ou maior desestabilização da categoria em mudança é o próprio traço, explícito ou implícito, que define a recategorização de um referente, quer tenha ele sido já introduzido no discurso para ser transformado, quer não tenha sido e se recategorize apenas mentalmente, no próprio momento em que o anafórico remete indiretamente à sua âncora. (CAVALCANTE, 2005, p. 132).

Cavalcante, embora avance na teoria e proponha uma percepção do fenômeno também discursivo-cognitivo, ainda reitera uma concepção de recategorização apoiada em retomadas/remissões de expressões referenciais, ou seja, ainda há traços de elementos linguísticos que marcam o fenômeno.

Já Lima (2009, p. 42) se posiciona da seguinte forma:

Nosso tratamento da recategorização restringe-se aos casos de anáfora direta e indireta, por força mesmo do recorte da investigação. Temos ciência, porém, de que o processo recobre outros tipos de expressões 
referenciais, a exemplo das anáforas encapsuladoras (cf. VASCONCELOS DE SÁ, 2007). Contudo, a perspectiva de tratamento do fenômeno, nesses outros casos, não difere do estudo seminal de Apothéloz e ReichlerBéguelin (1995), no que tange ao foco nas funções discursivas, embora ocorra por caminhos mais bem sedimentados.

Vê-se que a autora reconhece os limites dos estudos da recategorização amparada apenas em elementos linguísticos, mas não avança numa discussão que traga este processo à luz dos elementos multimodais que recategorizam, já que, por recortes metodológicos, ampara-se na anáfora direta/indireta - até aqui, não era prevista esta mesma categoria com características multimodais. Para a autora, a recategorização

[...] se trata de um processo de natureza cognitivo-referencial, que deriva da categorização na atividade de referenciação. Esse pressuposto tem os seguintes desdobramentos: i) a recategorização nem sempre pode ser reconstruída diretamente no nível textual-discursivo, não se configurando apenas pela remissão ou retomada de itens lexicais [grifos nossos]; ii) em se admitindo (i), a recategorização deve, em alguns casos, ser (re)construída pela evocação de elementos radicados num nível cognitivo, mas sempre sinalizados por pistas linguísticas [grifos nossos], para evitar-se extrapolações interpretativas; iii) em decorrência de (ii), a recategorização pode ter diferentes graus de explicitude e implicar, necessariamente, processos inferenciais. (LIMA, 2009, p.57).

Como se vê nos nossos grifos, a autora reconhece que a recategorização não se limita à remissão/retomada de itens lexicais, mas parece generalizar quando marca a obrigatoriedade da sinalização linguística, o que, no nosso entender, faz com que continuem sendo deixados à margem elementos que também constroem a referência, como os aspectos multimodais.

Cavalcante e Custódio Filho (2010) e Custódio Filho (2011; 2012), por exemplo, avançam ao argumentar em favor de a Linguística Textual ter de considerar a integração de múltiplos fatores para a construção da referência e, por conseguinte, do sentido de um texto. Mesmo assim, pouco se investigou como a recategorização pode ser analisada a partir desses recursos. Vejamos como isso ocorre.

\section{RECURSOS MULTIMODAIS QUE RECATEGORIZAM}

À luz da LT, ainda nos faltam critérios de análise mais consistentes para investigar a construção do sentido em textos multimodais. Propomo-nos, neste trabalho, apenas reforçar a tese (nada nova, é verdade) de que eles contribuem para 
a construção do sentido no texto, muitas vezes recategorizando o referente e apontar como pode ser feita uma análise nesse sentido. Analisemos o primeiro texto:

(1)

Figura 2 - Recategorização do verbo

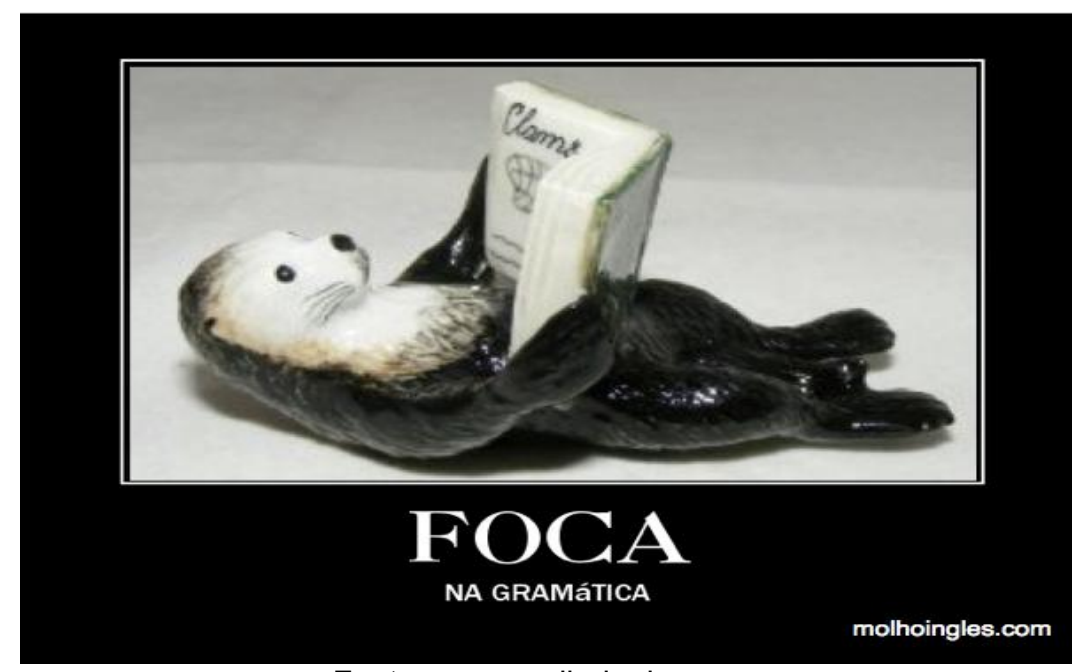

Fonte: www.molhoingles.com

Se não tivéssemos acesso à imagem, qual seria a interpretação desse exemplo? Provavelmente a construção de sentido seria efetuada a partir do verbo "focar", que indica pôr em foco, concentrar-se em algo, neste caso, na gramática. Ao nos depararmos com a junção da imagem e dos elementos linguísticos, recorremos não apenas aos nossos conhecimentos referentes à língua para a construção do sentido, pois a utilização do animal foca segurando a gramática gera uma significação que só é compreendida devido à união dos conhecimentos linguístico e enciclopédico.

Sendo assim, o então verbo "focar" acaba sendo recategorizado para o substantivo foca, a partir do momento em que o leitor faz a recuperação, por meio de recursos multimodais, do sentido de foca enquanto animal. Veja-se aí a importância do conhecimento linguístico necessário para a construção do sentido - quando o verbo "focar" é recategorizado para um substantivo "foca" a partir da leitura de recursos semióticos não linguísticos. Isso comprova o quanto um novo letramento no caso o visual - precisa ser considerado para que seja possível a compreensão de textos dessa natureza. Vejamos outro caso. 
(2)

\section{Figura 3 - Recategorização dos elementos do Facebook}

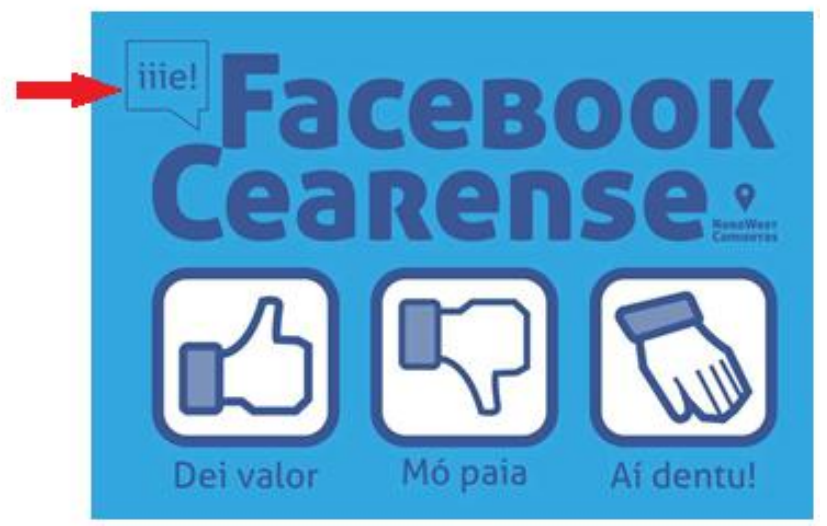

Fonte: www.facebook.com

Diferentemente do texto anterior, que tem recategorizado o referente que se ancora em expressões referenciais linguísticas, o exemplo (2) mostra como seria o Facebook de um internauta cearense. $O$ texto humorístico apoia-se em elementos socioculturais do estado nordestino que são utilizados em situações de comunicação informais. Inicialmente, atentando para a seta, vemos o termo "iiie!", que faz remissão ao uso dessa interjeição por cearenses quando estão diante de uma situação de gozação. Como o intuito do texto é mostrar marcas da variante linguística cearense, possivelmente apenas internautas que tenham contato com essa variante conseguirão recuperar esse sentido.

O que é interessante neste exemplo é mostrar como um dos signos utilizados pelo Facebook pode ser recategorizado neste caso. Os usuários desse site reconhecem o signo (政) como like ou, na versão brasileira, "curtir". Ele é utilizado pelo internauta para marcar postagens de outros usuários que são julgadas interessantes ou que são compatíveis com seu ponto de vista. A partir do momento em que o usuário "curte" uma postagem, passa a receber atualizações dela constantemente. A legenda "Dei valor" aponta uma gíria cearense que resgata o mesmo sentido do "curtir" do Facebook: equivale a "gostei". Possivelmente um usuário que não conhece gírias cearenses construiria esse sentido resgatando informações do seu conhecimento de mundo, por analogia ao signo "Curtir". É na segunda e terceira figuras que acontece devidamente a recategorização: "mó paia" é outra gíria cearense que indica algum tipo de reprovação. Entretanto, o signo mostrado na imagem não existe no Facebook. $O$ enunciador recategoriza o signo 
que seria equivalente a "Não curtir" a partir do momento em que ele inverte para baixo o signo utilizado do Facebook e, como consequência, propicia a construção do sentido do texto, claramente humorístico. O leitor, então, tem de se apoiar no conhecimento enciclopédico acerca do que é o elemento semiótico que representa o "Curtir" e não necessariamente em um elemento linguístico.

Já a terceira figura, cuja legenda é "Aí dentu", mostra uma outra gíria propagada por um programa de televisão cearense. Assim como os outros termos, a construção do sentido só é eficaz se o leitor tiver conhecimentos enciclopédicos sobre a simbologia utilizada em situações também informais para denotar alguma negação. No programa, também humorístico, os personagens utilizam a gíria para mostrar que não concordam com seu interlocutor. Multimodalmente, além da expressão, isso também pode ser marcado pelo uso da mão em riste e com um movimento para frente, assim como é mostrado na figura. Observe que o enunciador desse texto resgatou esse conhecimento de mundo sobre a expressão "aí dentu" para estabelecer um paralelismo com a figura "Curtir", própria do Facebook; e acaba recategorizando-a num primeiro momento quando se utiliza a gíria "Dei valor"; e "mó paia", esta apoiada numa inversão do signo original.

Em suma, este exemplo mostra que o referente "Curtir", do Facebook, já é largamente utilizado - não só na rede social - com o elemento multimodal ( $₫)$. Embora saibamos que os estudos da recategorização, a priori, foram pensados para dar conta de elementos linguísticos, propomos alargar esse conceito para dar conta também de elementos multimodais. Vejamos outro exemplo.

Figura 4 - Recategorização das festas de fim de ano

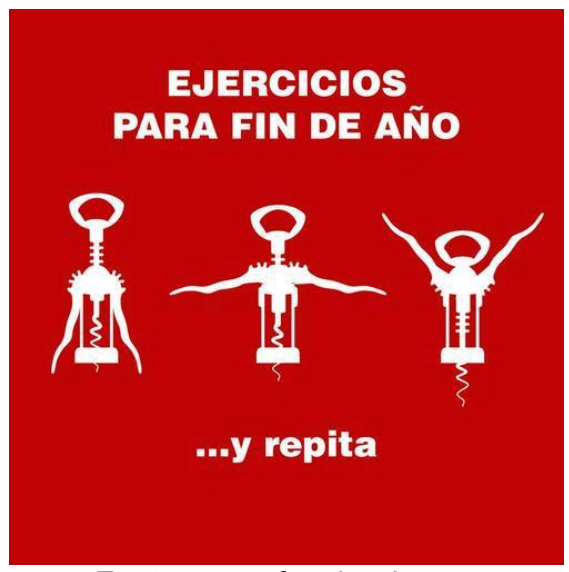

Fonte: www.facebook.com 
O exemplo (3), cujos elementos linguísticos estão em espanhol, deve ser assim traduzido: "Exercícios para fim de ano [...] e repita". Ao ler o texto, o referente que tende a ser construído são os exercícios físicos que podem ser feitos no fim do ano. A figura que é mostrada em três momentos no centro do texto ajuda na construção desse sentido: trata-se de um mecanismo multimodal que demonstra uma narrativa - mostrada pela sequência de ações - que deveria ser desenvolvida por um indivíduo, já que, num primeiro momento, parece tratar-se do movimento de braços de uma pessoa. Neste caso, apelando para o conhecimento de mundo dos leitores, parece tratar-se dos exercícios que podem ser feitos numa aula de ginástica, por exemplo, onde há constantes e repetitivos movimentos com o corpo. Entretanto, a silhueta do objeto não é a de um ser humano, mas a de um sacarolhas.

Ao se deparar com isso, o referente "Exercícios de fim de ano", a priori, identificado como uma alusão às aulas de ginástica, é recategorizado, já que o objeto mostrado serve para retirar rolhas de garrafas. O sentido do texto ganha novos contornos, já que, na verdade, o que se quer enaltecer é que o único exercício que deve ser feito no fim do ano é o de abrir as garrafas de prováveis confraternizações típicas da época. Subentende-se, então, uma ideia contrária à de exercitar-se fisicamente, já que o leitor, apoiando-se no seu conhecimento enciclopédico, provavelmente sabe que em festas há bebida e comida fartas, o que favorece a ideia de que não há preocupações quanto aos exercícios físicos, mas tão somente ao fato de se engordar no período de festividades.

\section{CONSIDERAÇÕES FINAIS}

$\mathrm{Na}$ LT, existe ainda certa dificuldade em elencar critérios que deem conta de recursos multimodais para a construção do sentido do texto, já que toda a teoria pensada até meados dos anos 2000 considerava texto apenas aqueles enunciados que englobassem elementos linguísticos. Este trabalho teve o propósito de mostrar, corroborando com os atuais estudos da Referenciação (CAVALCANTE, 2012; CUSTÓDIO FILHO, 2011), que os elementos multimodais também são importantes para a construção de objetos de discurso na interação, além de ser possível dizer que eles também podem ser responsáveis pela recategorização de referentes. 


\title{
NOTAS
}

${ }^{1}$ Mestre e Doutoranda em Linguística pela Universidade Federal do Ceará.

2 Docente do curso de Letras. Mestre e Doutorando em Linguística pela Universidade Federal do Ceará.

${ }^{6}$ Há uma gama de trabalhos que discutem as características multimodais dos gêneros, assunto, a priori, constitutivo da agenda de estudos da LT, mas ficam amparados pelos pressupostos da Semiótica Social (cf. COSTA, 2010) ou Análise do Discurso Crítica (MOZDZENSKI, 2006; GOMES, 2007), muito provavelmente pela falta de critérios da Linguística de Texto para dar conta de tais elementos.

\section{RECATEGORIZATION AND CONSTRUCTION OF MEANING IN MULTIMODAL TEXTS}

\begin{abstract}
Although there are studies on multimodal elements for more than one decade ago in Linguistics studies, only in the past five years the Text Linguistics took into account non verbal semiotic resources in their discoursive/text analyzes. This paper aims to investigate how multimodal resources can also be treated as referring expressions that recategorizate discourse objects. For this, we investigated a corpus of ten multimodal texts published on social networking sites whose characteristic is the recategorization of the referent. The results show that the visual elements belonging to the composition of multimodal texts are also central to the construction of the meaning of the text, so that they are often responsible for the recategorization process.
\end{abstract}

Keywords: Meaning construction. Recategorization. Multimodal texts.

\section{REFERÊNCIAS}

APOTHÉLOZ, D. ; REICHLER-BÉGUELIN, M. J. Construction de la référence et stratégies de désignation. In: BERRENDONNER ; REICHLER-BÉGUELIN, M-J. (Eds.). Du sintagme nominal aux objects-de-discours: SN complexes, nominalizations, anaphores. Neuchâtel: Institute de linguistique de l'Université de Neuchâtel, 1995. p. 227-271.

BENTES, A. C.; ALVES FILHO, F.; RAMOS, P. Enfrentando desafios no campo de estudos do Texto. In: BENTES, A. C.; LEITE, M. Q. (Org.). Linguística de texto e análise da conversação: panorama das pesquisas no Brasil. São Paulo: Cortez, 2010. p. 389-428.

CAVALCANTE, M. M. O processo de recategorização sob diferentes parâmetros. In: XX JORNADA NACIONAL DE ESTUDOS LINGUÍSTICOS - GRUPO DE ESTUDOS 
LINGÜÍSTICOS DO NORDESTE, 2004, João Pessoa. Anais... João Pessoa: Idéia, v. 1 , p. $14-18$..

.Anáfora e deixis: quando as retas se encontram. In: $\mathrm{KOCH}, \mathrm{I}$. V.; MORATO, E. M. M.; BENTES, A. C. Referenciação e discurso. São Paulo: Contexto, 2005, p. 125-149.

. Os sentidos do texto. São Paulo: Contexto, 2012.

CAVALCANTE, M. M.; SANTOS, L. W. Referenciação e marcas de conhecimento partilhado. Linguagem em (Dis)curso, Tubarão, SC, v. 12, n. 3, p. 657-681, set./dez. 2012.

COSTA, R. R. A TV na Web: percursos da reelaboração de gêneros audiovisuais na era da transmídia. 2010. 173 f. Dissertação (Mestrado em Linguística) - Programa de Pós-graduação em Linguística, UFC, Fortaleza, 2010.

CUSTÓDIO FILHO, V. Múltiplos fatores, distintas interações: esmiuçando o caráter heterogêneo da referenciação. 330 f. 2011. Tese (Doutorado em Linguística) Programa de Pós-graduação em Linguística, Universidade Federal do Ceará, Fortaleza, 2011.

. Reflexões sobre a recategorização referencial sem menção anafórica. Linguagem em (Dis)curso, Tubarão, SC, v.12, n. 3, p. 839-858, set./dez. 2012.

CUSTÓDIO FILHO; V.; CAVALCANTE, M. M. Revisitando o estatuto do texto. Revista do Gelne, Fortaleza, v. 12, n. 2, 2010.

GOMES, M. C. A. Gêneros da gídia: configurando o gênero reportagem-publicidade. In: IX SIMPÓSIO INTERNACIONAL DE GÊNEROS TEXTUAIS - SIGET, 2007, Tubarão. Anais... Tubarão: Unisul, 2007. v. 1. p. 1344-1356.

HODGE, R.; KRESS, G. Social semiotics. Ithaca, New York: Cornell University Press, 1988.

KOCH, I. V. Introdução à linguística textual. São Paulo: Martins Fontes, 2004.

KOCH, I. G. V.; ELIAS, V. Ler e compreender os sentidos do texto. São Paulo: Contexto, 2006.

KRESS, G.; VAN LEEUWEN, T. Reading images: the grammar of visual design. 2 ed. London; New York: Longman, 2006 [1996].

MOZDZENSKI, L. A cartilha jurídica: aspectos sócio-históricos, discursivos e multimodais. 195 f. 2006. Dissertação (Mestrado em Letras e Linguística) Programa de Pós-graduação de Letras e Linguística, Universidade Federal de Pernambuco, Recife, 2006. 
PINHEIRO, C. Processos referenciais em textos multimodais: aplicação ao ensino. In: SIMPÓSIO INTERNACIONAL DE ENSINO DE LÍNGUA PORTUGUESA, 2011, Uberlândia. Anais.... Uberlândia: EDUFU, 2012, v. 2, n. 1.

LIMA, S. M. C. Entre os domínios da metáfora e da metonímia: um estudo de processos de recategorização. 205 f. 2009. Tese (Doutorado em Linguística) Programa de pós-graduação em Linguística, Universidade Federal do Ceará, Fortaleza, 2009.

RAMOS, P. Estratégias de referenciação em textos multimodais: uma aplicação em tiras cômicas. Linguagem em (Dis)curso, Tubarão, SC, v. 12, n. 3, p. 743-763, set./dez. 2012.

SANTOS, L. W.; CUBA RICHE, R.; TEIXEIRA, C. de S. Análise e produção de textos. São Paulo: Contexto, 2012. 